\title{
Anxiety and the management of asthma in an adult outpatient population
}

\author{
Maria Cordina, Anthony G. Fenech, Josanne Vassallo and Joseph M. Cacciottolo
}

\begin{abstract}
:
Background: Review of the literature suggests that anxiety is more common among patients with asthma than among the general population, yet it does not appear to be given the attention it deserves as part of the overall management of asthma. The aim of this study was to investigate the relationship between anxiety and asthma management, in terms of Global Initiative for Asthma steps, lung function and medication.

Methods: A total of 201 consecutive patients with respiratory physician-diagnosed asthma were recruited from an adult outpatient asthma clinic. Participants underwent a sociodemographic review, and a medical interview which included a detailed drug history. Forced expiratory volume in 1 second $\left(\mathrm{FEV}_{1}\right.$ ) and peak expiratory flow (PEF) values were recorded using a Micro Medical ${ }^{\circledR}$ portable spirometer. The level of anxiety was assessed using the Beck Anxiety Inventory (BAI).

Results: A total of $51.5 \%$ of participants registered clinically significant levels of anxiety. Of these only $21 \%$ had already been diagnosed and were receiving treatment. Females reported significantly higher BAI scores than males $(p<0.01)$. More females $(66.3 \%)$ registered clinically significant levels of anxiety as compared with males $(33.7 \%)(p<0.05)$. There was a positive correlation between the BAI score and the prescribed dose of inhaled glucocorticoids $\left(r_{\mathrm{s}}=0.150, p<0.05\right)$ and between anxiety and GINA treatment step $\left(r_{\mathrm{s}}=0.139, p<0.05\right)$. There was also a positive correlation between anxiety and the number of medicines taken by patients $\left(r_{\mathrm{s}}=0.259, p<0.001\right)$.

Conclusions: Physicians treating patients with asthma should be sensitised to the association between asthma and anxiety, and should also consider assessing patients for the possibility of anxiety disorders as part of asthma management plans.
\end{abstract}

Keywords: asthma, anxiety, lung function, medication

\section{Introduction}

The focus of treatment decisions in asthma should be based on control of the condition [GINA, 2008]. The current trend in asthma management is therefore aimed at addressing the 'unmet needs in asthma' which arise from factors related to poor disease control [Rabe et al. 2004]. The overall aim is to achieve better control of asthma with patients leading as normal a life as possible. Asthma management guidelines give a clear definition of control: this is not limited to optimising lung function but incorporates symptom control, a fulfilling lifestyle, proper use of rescue/reliever medication, and reduction in the number and severity of exacerbations. Increasing emphasis is being placed on the patient being a full partner in the management decisions to achieve control [GINA, 2008; NAEEP, 2007]. This can only be achieved through a strong doctor-patient relationship, and one which allows for enough time to make a holistic assessment of patients' needs, addressing any underling problems and concerns. Any psychiatric symptoms, psychological disturbance and perception of asthma should also be assessed, as these factors could contribute significantly to diminished control of asthma [Bosley et al. 1996].

The relationship between asthma and anxiety has long been established [Smoller and Otto, 1998; Yellowlees and Kalucy, 1990] and various studies have established that anxiety is more common in persons with asthma than in the general population. Persons with asthma have been found to be
Ther Adv Respir Dis (2009) 3(5) 227-233 DOI: $10.1177 /$ 1753465809347038

(C) The Author(s), 2009. Reprints and permissions: http://www.sagepub.co.uk/ journalsPermissions.nav
Correspondence to: Maria Cordina, BPharm. (Hons), PhD (QUB)

Department of Pharmacy, Faculty of Medicine and Surgery, University of Malta, Msida, Malta maria.cordinala um.edu.mt

Anthony G. Fenech Department of Clinical Pharmacology and Therapeutics, Faculty of Medicine and Surgery, University of Malta, Msida, Malta

Josanne Vassallo Joseph M. Cacciottolo Department of Medicine, Faculty of Medicine and Surgery, University of Malta, Msida, Malta 
twice as likely to report frequent mental distress (FMD) as compared with those without asthma. Asthmatics with FMD were more likely to report frequent anxiety symptoms [Strine et al. 2004]. Goodwin et al. [2004] reported elevated rates of depressive and anxiety disorders among young adults with asthma as compared with their counterparts without asthma in the community. A population-based study of adolescents with asthma found that those with an anxiety or depressive disorder reported significantly more asthma symptoms than those not presenting with these disorders [Richardson et al. 2006]. Studies have also found elevated rates of asthma amongst patients with anxiety disorders. Higher rates of asthma were found among adolescent psychiatric inpatients with post-traumatic stress disorder (PTSD) [Koltek et al. 1998] and similar findings were reported in primary care patients [Weisberg et al. 2002]. The association between asthma and anxiety appears to exist independently of the degree of severity of asthma [Valenca et al. 2006; Brinke et al. 2001].

The possibility of anxiety as a risk factor for developing asthma was examined by Jonas et al. [1999] and it was found that the relative risks of developing asthma were increased significantly in nonsmokers with high and intermediate levels of anxiety symptoms. The presence of anxiety in patients with asthma has been associated with suboptimal asthma-related quality of life and is possibly linked to decreased adherence to therapy [Lavoie et al. 2006; Cluley and Cochrane, 2001].

While the link between asthma and anxiety is evident, the causal direction between anxiety and poor disease management and control remains unclear. It may either be a consequence of, or a contributor to the condition. A Swiss community-based, prospective longitudinal study investigated whether active asthma predicted subsequent panic disorder and whether tendency to panic predicted active asthma. The results indicate both that active asthma predicted subsequent panic disorder and vice-versa. This effect was more pronounced among women and persons under the age of 30 years. However, the major limitation of this study was that the diagnosis of asthma was self-reported [Hasler et al. 2005]. The aim of this study is to investigate the relationships between patient anxiety and asthma management, in terms of GINA step, lung function and medication.

\section{Methods}

\section{Study subjects}

A consecutive series of outpatients with respiratory physician-confirmed asthma was recruited from the adult asthma clinic at St Luke's Hospital, Malta over a 3-month period. Patients were eligible for inclusion if they had a primary diagnosis of asthma and were receiving inhaled glucocorticoid therapy for a duration of 12 months or more. A total of 215 patients presented at the asthma clinic, all of whom were screened for inclusion in the study. A total of 14 patients did not satisfy the criteria for inclusion in the study (10 patients had been on inhaled glucocorticoid therapy for less than a year, one patient was not on inhaled glucocorticoids and three patients refused to participate). Informed consent was obtained from all patients and ethical approval for the study was obtained from the Research Ethics Committee of the University of Malta.

\section{Study design}

Eligible participants underwent a medical interview to document sociodemographic characteristics, medical history and a detailed drug history covering their asthma medication as well as any other medication they were concurrently taking. All information was verified by cross-referencing to the patients' medical files. Information regarding prescribed asthma medication was used to classify patients according to one of the five asthma treatment steps as defined by GINA. Patients also underwent spirometry testing in line with European Respiratory Society guidelines [European Respiratory Society, 1993]. Forced expiratory volume in one second $\left(\mathrm{FEV}_{1}\right)$ and peak expiratory flow (PEF) were recorded using a Micro Medical ${ }^{\circledR}$ portable spirometer.

\section{Assessment tool}

The level of anxiety was assessed using the Beck Anxiety Inventory (BAI). The BAI consists of 21 descriptive statements of anxiety symptoms which are rated on a four-point scale ranging from 0 to 3. The maximum score is 63 points. Total scores from 0 to 7 are considered to reflect a minimal level of anxiety, scores of 8-15 indicate mild anxiety, scores of 16-25 reflect moderate anxiety and scores of 26-63 indicate severe anxiety. A clinically significant level of anxiety was defined by a score of $\geq 16$ on the BAI [Beck and Steer, 1993]. 


\section{Data analysis}

The data were analysed using SPSS version 15. Spearman rank order correlation coefficient was used to determine relationships between anxiety and age, prescribed dose of inhaled glucocorticoid, GINA step, FEV ${ }_{1}$, PEF and the number of different types of medicines patients were taking. Spearman rank order correlation coefficient was used to determine the relationship between lung function parameters of $\mathrm{FEV}_{1}$ and $\mathrm{PEF}$ with prescribed dose of inhaled glucocorticoid and GINA step. The Mann-Whitney test was used to determine relationships between $\mathrm{FEV}_{1}$, gender and anxiety. The Kruskal-Wallis test was used to determine relationships between anxiety and comorbidities. For the purpose of analysing GINA step and anxiety, steps 4 and 5 were combined. A $p$-value of $<0.05$ was considered significant.

\section{Results}

The characteristics of the study sample are summarised in Table 1. A total of $58 \%$ had percentage predicted $\mathrm{FEV}_{1}$ of $\geq 80 \%, 23 \%$ had a percentage predicted $\mathrm{FEV}_{1}$ between $60 \%$ and $79 \%$, and $19 \%$ had a percentage predicted $\mathrm{FEV}_{1}$ of $<60 \%$. Females, had a higher mean percentage predicted $\mathrm{FEV}_{1}$ (females: $85 \pm 2.63$, males: $77.8 \pm 2.4, p<0.05)$. The majority of patients were being treated at GINA steps 4 and 5 with $57.7 \%$ receiving a high $(>1000 \mu \mathrm{g}$ beclomethasone or equivalent) daily dose of inhaled glucocorticoids. A total of $45.7 \%$ of patients studied, had chronic comorbid conditions. There were predominantly cardiovascular problems $(29.4 \%)$, anxiety/depression (13.4\%), other respiratory disorders (mainly rhinitis), $(10 \%)$ and diabetes mellitus (7\%).

The mean BAI score was $17.7 \pm 0.8$ (SEM), with $51.5 \%$ registering clinically significant levels of anxiety $(\mathrm{BAI} \geq 16)$ as presented in Table 2 . Of these only $21 \%$ had their anxiety formally diagnosed and were receiving treatment for such. Females reported significantly higher BAI scores than males $(19.6 \pm 1.06$ versus $15.1 \pm 1.2$, $p<0.01)$. More females registered clinically significant levels of anxiety as compared with males $(66.3 \%$ versus $33.7 \%, p<0.05)$. There was a positive correlation between the BAI score and the prescribed dose of inhaled glucocorticoids $\left(r_{\mathrm{s}}=0.150, p<0.05\right)$. A positive correlation was also established between anxiety and GINA treatment step $\left(r_{\mathrm{s}}=0.139, p<0.05\right)$. Further analysis revealed a positive correlation between anxiety
Table 1. Characteristics of patients.

\begin{tabular}{ll}
\hline Characteristic & \\
\hline Total & 201 \\
Females & $118(58.7 \%)$ \\
Age mean (years) & $48.9 \pm 1.25$ \\
Age range (years) & $17-83$ \\
FEV 1 (mean \% predicted) & $82.01 \pm 1.67$ \\
PEF (mean \% predicted) & $77.53 \pm 1.79$ \\
Patient treatment & \\
(GINA guidelines) & \\
Step 2 & $57(28.4 \%)$ \\
Step 3 & $26(12.9 \%)$ \\
Step 4 & $108(53.7 \%)$ \\
Step 5 & $10(5 \%)$ \\
Prescribed medicines mean & $3.5 \pm 0.13$ \\
Range & $1-9$ \\
Patients receiving treatment & $27(13.4 \%)$ \\
$\quad$ for anxiety & \\
\hline & \\
\hline
\end{tabular}

Table 2. Severity of anxiety using the Beck Anxiety Inventory (BAI).

\begin{tabular}{|c|c|c|c|c|c|c|}
\hline \multirow{2}{*}{$\begin{array}{l}\text { Anxiety level } \\
\text { (BAl Score) }\end{array}$} & \multicolumn{2}{|c|}{ Male } & \multicolumn{2}{|c|}{ Female } & \multicolumn{2}{|c|}{ Total } \\
\hline & No & $\%$ & No & $\%$ & No & $\%$ \\
\hline Minimal (0-7) & 19 & 23.0 & 20 & 16.9 & 39 & 19.4 \\
\hline Mild (8-15) & 29 & 34.9 & 29 & 24.6 & 58 & 28.9 \\
\hline Moderate (16-25) & 21 & 25.3 & 33 & 28.0 & 54 & 26.6 \\
\hline Severe $(26-63)$ & 14 & 16.8 & 36 & 30.5 & 50 & 24.9 \\
\hline
\end{tabular}

and the number of medicines taken by patients $\left(r_{\mathrm{s}}=0.259, p<0.001\right)$. When analysed independently both genders showed a positive correlation between the number of medicines being taken and anxiety (males: $r_{\mathrm{s}}=0.267, p<0.05$, females: $\left.r_{\mathrm{s}}=0.260, p<0.01\right)$.

Negative correlations were established between percentage predicted $\mathrm{FEV}_{1}$ and dose of prescribed inhaled glucocorticoid $\left(r_{\mathrm{s}}=-0.352\right.$, $p<0.01)$, PEF and dose of prescribed inhaled glucocorticoid $\left(r_{\mathrm{s}}=-0.267, p<0.01\right)$, percentage predicted $\mathrm{FEV}_{1}$ and GINA step $\left(r_{\mathrm{s}}=\right.$ $-0.397, p<0.01)$, and PEF and GINA step $\left(r_{\mathrm{s}}=-0.296, p<0.01\right)$. There was no association between the objective asthma-related variables of percentage predicted $\mathrm{FEV}_{1}$ and PEF and anxiety. Age, or the number of diagnosed comorbid conditions, were not significantly associated with anxiety.

\section{Discussion}

The results of the present study are consistent with and extend previous findings related to the association between asthma and anxiety. 
Our data confirm a high prevalence of anxiety among patients with asthma $(51.5 \%)$. These findings fall in the upper end of the prevalence spectrum of anxiety in asthma as reported in the literature [Katon et al. 2004] and are in line with a similar study which reported a $52.3 \%$ prevalence of anxiety carried out in an outpatient asthma unit setting in Brazil [Nasciemento et al. 2002]. The high level of anxiety documented in the present study did not have any impact on lung function, as there was no correlation between the objective measures of $\mathrm{FEV}_{1}$ or $\mathrm{PEF}$ with anxiety; this finding is also supported by other studies [Krommydas et al. 2004; Rimingtom et al. 2001]. It has been suggested that the association between asthma and anxiety may be due to the central role of respiratory factors in anxiety disorders. Anxiety itself may lead to hyperventilation, irrespective of the degree of objective pulmonary impairment, and in the presence of some form of airways obstruction, it may result in increased breathlessness [Carr, 1998]. As in the general population, the majority of the patients with clinically significant anxiety $(79 \%)$ were undiagnosed and untreated, a finding also supported by other studies [Valenca et al. 2006; Goodwin, 2003]. Various barriers have been cited with regards to the diagnosis and treatment of anxiety, such as the stigma perceived by patients, who would tend to exaggerate their somatic complaints, to health care professionals lacking interest and time to make the appropriate diagnosis [Kunik et al. 2005]. An additional possibility is the limited availability of integrated mental health services at community level [Rutz, 2002]. Furthermore, studies related to physician-patient interaction in asthma management have shown that patients' concerns may not be sufficiently addressed due to lack of time and poor communication [Canonica et al. 2007; Moffat et al. 2006].

Women reported significantly higher levels of anxiety than males (19.6 versus 15.1 ) despite registering significantly higher mean levels of percentage predicted $\mathrm{FEV}_{1}(85 \%$ versus $77.8 \%)$. It is well established that women are more likely to develop anxiety disorders then men [Pigott, 1999] and the BAI manual [1993] also indicates that the BAI score for women may be an average of four points higher than for men. This trend has also been reflected in other studies related to anxiety and respiratory disease [Moussas et al. 2008]. In a study of postmenopausal women aged 50 years and over, Smoller et al. [2003] reported that women with a history of asthma were more likely to report full-blown panic attacks. This relates well with the findings in the present study whereby $66.7 \%$ of women who reported clinically significant anxiety were aged 50 years and over. The increased levels of anxiety in women notwithstanding better percentage predicted $\mathrm{FEV}_{1}$ is supported by Carr et al.'s [1996] work, which also found a positive association with lung function. There are, however, other studies which have found no gender differences in the levels of anxiety between males and females [Deshmukh et al. 2008].

Higher levels of anxiety were positively associated with high doses of inhaled glucocorticoids and consequently management at higher GINA steps. Considering that the majority of the study sample $(58 \%)$ had a predicted $\mathrm{FEV}_{1}$ of over $80 \%$ and $57.7 \%$ of population were receiving high doses of inhaled glucocorticoids, it is pertinent to question the basis for the sustained prescription of high doses of inhaled glucocorticoids, especially since at each patient visit to asthma clinic, lung function tests are performed. Our data did, however, produce a negative correlation between lung function $\left(\mathrm{FEV}_{1}, \mathrm{PEF}\right)$ and prescribed dose of inhaled glucocorticoids as well as GINA step, indicating the lower the lung function the higher the treatment step. This result also provides validity to our population reflecting the study by Rimington et al. [2001]. Other studies failed to document a relationship between $\mathrm{FEV}_{1}, \mathrm{PEF}, \mathrm{FVC}$ and physicians' prescribing decisions [Hyland et al. 1993].

It is possible that prescribing decisions are mostly based on patients' reported symptoms without giving sufficient weight to lung function values. It is also possible, that physicians could treat a psychological problem as a medical problem and overprescribe inhaled glucocrticoids instead of identifying and treating the underlying anxiety [Dirks et al. 1979]. An additional factor worth considering is that medications used to control asthma (i.e. inhaled glucocorticoids, adrenoreceptor agonists and theophylline) have all been implicated in provoking anxiety. In our sample, all patients had been on inhaled glucocorticoids for over a year, $5 \%$ were on long-term low-dose oral steroids, $11.4 \%$ had taken a rescue course within the preceding 3 months, $10.4 \%$ were taking steroids intranasally, $10 \%$ were additionally taking long-acting beta adrenergic agonists and $9.4 \%$ were taking theophylline. All the 
patients in our study were taking inhaled salbutamol on an 'as required' basis. All these medications could have contributed to the high anxiety levels recorded.

Our data revealed a relationship between the number of different medications taken by the patient and anxiety levels. The higher the number of medications, the higher the anxiety level recorded; this fact could also in itself be an additional contributing factor to the high anxiety levels. Patients suffering from respiratory and cardiovascular disease are particularly prone to polypharmacy [Bjerrum et al.1998] which in turn is likely to lead to inappropriate use of medicines. The frequency of inappropriate medication use rises with the number of medicines being taken [Steinmen et al. 2006] and it follows that in encounters with patients, appropriate multifaceted, multidisciplinary interventions should be aimed at optimising use of medications.

There are a number of limitations to the present study. The group of patients studied attended a respiratory specialist-run outpatient asthma clinic. Patients attending this clinic are perceived to fall in the moderate-to-severe spectrum of severity and do not mirror the general population. The level of anxiety was self-reported and was not validated by a professional structured diagnostic assessment. The study did not record data relating to patients' symptoms, which could have given a more comprehensive picture of the study population. The present study was an observational, uncontrolled, cross-sectional study and therefore cannot determine if the observed associations are causal or not.

Physicians treating patients with asthma should be sensitised to the association between asthma and anxiety and should also consider assessing the patient for possibility of anxiety disorders. A systematic evaluation for possible comorbid anxiety disorders should be a part of asthma management [Boulet, 2009]. While the diagnosis of anxiety disorders in patients with asthma may be challenging, it may at times be more appropriate to treat the anxiety state rather than step up the medication. This approach could have a steroid-sparing effect, achieving control at the lowest possible dose. Judicious use of anxiolytic medication is necessary due to negative effect of certain medications within this class (e.g. benzodiazepines) on breathing. The use of alternative approaches to the management of anxiety in patients such as cognitive behaviour therapy [Deshmukh et al. 2007] may also help to achieve a positive outcome while avoiding the additional use of medicines.

\section{Conflict of interest statement}

None declared.

\section{References}

Beck, A.T. and Steer, R.A. (1993) Beck Anxiety Inventory Manual, The Psychology Corporation, Harcourt Brace: San Antonio.

Bjerrum, J., Sugaard, J., Hallas, J. and Kragstrug, J. (1998) Polypharmacy correlations with sex age and drug regimen. Eur f Clinc Pharmacol 54: 197-202.

Bosley, C.M., Corden, Z.N. and Cochrane, G.M. (1996) Psychological factors and asthma. Resp Med 90: 453-457.

Boulet, L.-P. (2009) Influence of comorbid conditions on asthma. Eur Respir f 33: 897-906.

Brinke, T.A., Ouwerkek, M.E., Bel, E.H. and Spinhoven, P. (2001) Similar psychological characteristics in mild and severe asthma. F Psycho Res 50: 7-10.

Canonica, G.W., Baena-Cagnani, C.E., Blaiss, M.S., Dahl, R., Kaliner, M.A. and Valvovirta, E.J. (2007)

Unmet needs in asthma: Global Asthma Physician and Patient (GAPP) Survey: global adult findings. Allergy 62: 668-674.

Carr, R.E. (1998) Panic disorder and asthma: causes, effects and research implications. $\mathcal{F}$ Psychosom Res 44: 43-52.

Carr, R.E., Lehrer, P.M., Hochron, S.M. and Jackson, A. (1996) Effect of psychological stress on airway impedance in individuals with asthma and panic disorder. Abnorm Psychol 105: 137-141.

Cluley, S. and Cochrane, G.M. (2001) Psychological disorder in asthma is associated with poor control and poor adherence to inhaled steroids. Respir Med 95: 37-39.

Deshmukh, V.M., Toelle, B.G., Usherwood, T., O'Grady, B. and Jenkins, C.R. (2007) Anxiety, panic and adult asthma: a cognitive-behavioral perspective. Respir Med 101: 194-202.

Deshmukh, V.M., Toelle, B.G., Usherwood, T., O'Grady, B. and Jenkins, C.R. (2008) The association of comorbid anxiety and depression with asthmarelated quality of life and symptom perception in adults. Respirology 13: 695-702.

Dirks, J.F., Horton, D.J., Kinsman, R.A., Fross, K.H. and Jones, N.F. (1979) Patient and physician characteristics influencing medical decisions in asthma.

F Asthma Res 15: 171-178. 
European Respiratory Society (1993) Official statement on lung volumes and forced ventilatory flows. Eur Resp F 6(Suppl. 16): 5-40.

GINA (Global Initiative for Asthma) (2008) Global strategy for asthma management and prevention. Available at: http://www.ginasthma.com/ GuidelinesResources.asp? $11=2 \& 12=0$

Goodwin, R.D. (2003) Asthma and anxiety disorders. In: Brown, (ed.), Asthma: Social and Psychological factors and Psychosomatic Syndromes, Basel: Karger.

Goodwin, R.D., Fergusson, D.M. and Horwood, L.J. (2004) Asthma and depressive and anxiety disorders among young persons in the community. Psychol Med 34: 1465-1474.

Hasler, G., Gergen, P.J., Kleinbaum, D.G., Djdacic, V., Gamma, A., Eich, D. et al. (2005) Asthma and panic in young adults. A 20 year prospective community study. Am $\mathcal{F}$ Respir Crit Care Med 171: 1224-1230.

Hyland, M.E., Kenyon, C.A.P., Taylor, M. and Morice, A.H. (1993) Steroid prescribing for asthmatics: relationship with asthma symptom checklist and living with asthma questionnaire. Br $\mathcal{F}$ Clin Psychol 32: 505-511.

Jonas, B.S., Wagner, D.K., Lando, J.F. and Feldman, J.J. (1999) Symptoms of anxiety and depression as risk factors for development of asthma. F App Behav Res 4: $91-110$.

Katon, W.J., Richardson, L.R., Lozano, P. and McCauley, E. (2004) The relationship of asthma and anxiety disorders. Psychosom Med 66: 349-355.

Koltek, M., Wilkes, T.C. and Atkinson, M. (1998) The prevalence of post traumatic stress disorder in an adolescent in patient unit. Can F Psychiatry 43: 64-68.

Krommydas, G.C., Gourgoulianis, K.I., Angelopoulos, N.V., Kotrotsiou, E., Raftopulos, V. and Molyvdas, P.A. (2004) Depression and pulmonary function in outpatients with asthma. Respir Med 98: 220-224.

Kunik, M.E., Roundy, K., Veazey, C., Souchek, J., Richardson, P., Wray, N.P. et al. (2005) Surprisingly high prevalence of anxiety and depression in chronic breathing disorders. Chest 127: 1205-1211.

Lavoie, K.L., Bacon, S.L., Barone, S., Cartier, A., Ditto, B. and Labrecque, M. (2006) What is worse for asthma control and quality of life: Depressive disorders, anxiety disorders or both? Chest 130: 1039-1047.

Moffat, M., Cleland, J., van de, M.T. and Price, D. (2006) Sub-optimal patient and physician communications in primary care consultations; its relation to severe and difficult asthma. Prim Care Resp $\mathcal{F}$ 15: 159-165.
Moussas, G., Tselebis, A., Karkanias, A., Stamouli, D., Ilias, I., Bratis, D. et al. (2008) A comparative study of anxiety and depression in patients with bronchial asthma, chronic obstructive pulmonary disease and tuberculosis in a general hospital of chest diseases. Ann Gen Psychiatry 7: 7.

NAEEP (National Asthma Education and Prevention Programme) (2007) Expert Panel Report 3 (ERP3) Guidelines for the Diagnosis and Management of Asthma - Full Report. Available at: http:// www.nhlbi.nih.gov/guidelines/asthma/

Nascimento, I., Nardi, A.E., Valenca, A.M., Lopes, F.L., Mezzasalma, M.A. and Nascentes, R. (2002) Psychiatric disorders in asthmatic outpatients. Psychiatry Res 110: 73-80.

Pigott, T.A. (1999) Gender differences in the epidemiology and treatment of anxiety disorders. $\mathcal{F}$ Clin Psychiatry 60(Suppl. 18): 4-15.

Rabe, K.F., Adachi, M., Lai, C.K.W., Soriano, J.B., Vermeire, P.A. et al. (2004) Worldwide severity and control of asthma in children and adults: the global asthma insights and reality surveys. $\mathcal{F}$ Allergy Clin Immunol 114: 40-47.

Richardson, L.P., Lozano, P., Russo, J., McCauley, E., Bush, T. and Katon, W. (2006) Asthma symptom burden: relationship to asthma severity and anxiety and depression symptoms. Pediatrics 118: 1042-1051.

Rimington, L.D., Davies, D.H., Lowe, D. and Pearson, M.G. (2001) Relationship between anxiety, depression and morbidity in asthma adult patients.

Thorax 56: 266-271.

Rutz, W. (2002) Mental health in Europe: problems, advances, challenges. Acta Psychiatr Scand 104: 15-20.

Smoller, J.W. and Otto, M.W. (1998) Panic, dyspnea and asthma. Curr Opin Pulm Med 4: 40-45.

Smoller, J.W., Pollack, M.H., Wassertheil-Smoller, S., Barton, B., Hendrix, S.L., Jackson, R.D. et al. (2003) Prevalence and correlates of panic attacks in postmenopausal women. Arch Intern Med 163: 2041-2050.

Steinmen, M.A., Landefeld, M., Seth, C., Rosenthal, G.E., Berthenthal, D., Sen, S. et al. (2006)

Polypharmacy and prescribing in older people. $\mathcal{F} \mathrm{Am}$ Geriatr Soc 54: 1516-1523.

Strine, T.W., Ford, E.S., Balluz, L., Chapman, D.P. and Mokdad, A.H. (2004) Risk behaviours and health-related quality of life among adults with asthma: the role of mental health status. Chest 126: $1849-1854$.

Valenca, A.M., Falcao, R., Freire, R.C., Freire, R.C., Nascimento, I., Nascentes, R., Zin, W.A. et al. (2006) The relationship between the severity of asthma and 
co-morbidites with anxiety and depressive disorders. Rev Bras Psiqiatr 28: 206-208.

Weisberg, R.B., Bruce, S.E., Machan, J.T., Kessler, R.C., Culpepper, L. and Keller, M.B. (2002) Non psychiatric illness among primary care patients with trauma histories and post traumatic stress disorder. Psychiatr Serv 253: 848-854.

Yellowlees, P.M. and Kalucy, R.S. (1990)

Psychobiological aspects of asthma and consequent research implications. Chest 97: 628-629.
Visit SAGE journals online http://tar.sagepub.com

QSAGEJOURNALS

Online 